-Full Paper-

\title{
Gold Nanoparticles Enter Rat Ovarian Granulosa Cells and Subcellular Organelles, and Alter In-Vitro Estrogen Accumulation
}

\author{
Rosemary STELZER ${ }^{1)}$ and Reinhold J. HUTZ ${ }^{1,2}$ \\ ${ }^{1)}$ Department of Biological Sciences and ${ }^{2)}$ NIEHS Children's Environmental Health Sciences Core Center, University of \\ Wisconsin-Milwaukee, WI 53211, USA
}

\begin{abstract}
Nanoparticle technology refers to research and technology developed at the atomic or molecular level for materials of approximately 1-100 $\mathrm{nm}$ in length. Through accidental or involuntary exposure, nanoparticles are potentially toxic to the body, including reproductive organs. Ovarian granulosa cells play a major role in maintaining ovarian function, health, and female fertility. Since these cells are involved in steroidogenesis, we wished to evaluate whether nanoparticles affected them after traversing their membranes. Cells were co-incubated with $10 \mathrm{~nm}$ gold particles for up to $24 \mathrm{~h}$. Transmission electron micrographs were taken of GC treated with $10 \mathrm{~nm}$ gold particles in order to compare and contrast ultrastructural locations of nanoparticles with treatment. From micrograph comparisons of treated vs. untreated GC at various culture times, it appeared that some intracellular organelles involved in steroidogenesis were infiltrated and/or altered due to the presence of the nanogold particles. Medium samples were taken in order to determine estradiol-17beta (E2) accumulation/secretion by untreated vs. treated cells. GC incubated with $10 \mathrm{~nm}$ nanogold particles for 1,3, or $5 \mathrm{~h}$ were found to accumulate significantly increased amounts of estrogen compared with untreated cells. Conversely, at $24 \mathrm{~h}$ there was a significant attenuation with respect to controls. The data presented here provide insight into the toxicologic effects gold nanoparticles elicit on ovarian granulosa cells.
\end{abstract}

Key words: Estrogen, Granulosa cells, Nanoparticles, Steroidogenesis, Transmission electron microscopy

(J. Reprod. Dev. 55: 685-690, 2009)

N anomaterial technology has become a dynamic and exciting topic in biology over the past ten years. A decade ago nanoparticles were studied because of their size- dependent physical and chemical properties. Now they have entered a commercial exploration period [1]. Nanomaterials come in a variety of shapes, sizes, and elemental forms and are currently produced in a wide variety of types for a plethora of applications; fullerenes, carbon nanotubes, metal and metal oxide particles, polymer nanoparticles, and quantum dots are among the most common [2-5]. At these "nano" sizes, the toxicologic effects of common elements such as carbon, silicon, gold and titanium have not been studied very closely.

In order for nanoparticles to exert toxicologic effects they must first cross the cell membrane. It is important to study the process by which nanoparticles gain access to the cell because of their possible toxicologic and health implications [6-18]; however, to date there have been few studies on this area of concern. The increased use of nanoparticles in research, medicine, and the manufacture of consumer products, therefore, creates an urgent need to test the toxic potential of these materials. Considering that nanoparticles can travel to distant locations in the body and move across cell membranes of many types of cells, it is certainly conceivable that nanoparticles travel into GC of the ovarian follicle and disturb steroidogenesis. Therefore, in this study we evaluated the effects of gold nanoparticles on rat GC and organelles involved in steroid synthesis. We used gold nanoparticles because they have the unique ability to spontaneously coat themselves with proteins and use endocytosis to gain access to the cytoplasm and cellular

Accepted for publication: August 28, 2009

Published online in J-STAGE: September 29, 2009

Correspondence: R Hutz (e-mail: rjhutz@uwm.edu) organelles. Gold nanoparticles are also easily visualized by electron microscopy. We hypothesize that these particles will enter ovarian granulosa cells and negatively affect their steroidogenic capabilities. Our aims are (1) to observe whether gold nanoparticles can cross granulosa cell membranes and enter or otherwise affect specific organelles; and (2) to observe gold nanoparticle effects on steroidogenesis by granulosa cells in culture.

\section{Materials and Methods}

\section{Exposure of ovarian granulosa cells to $10 \mathrm{~nm}$ nanogold particles}

Adult female Sprague Dawley rats (Charles River Laboratories, Wilmington, MA) (mean age 234 days, showing two consecutive 4-day estrous cycles), were evaluated as to the day of their cycle by vaginal swabbing. Vaginal swabbing was followed by injection of 30 IU equine chorionic gonadotropin (eCG) (Sigma Aldrich, St. Louis, MO) on metestrus to stimulate follicle growth. The animals were sacrificed approximately $48 \mathrm{~h}$ later [19]. There were typically 10 to 15 preovulatory-sized follicles per ovary at time of sacrifice.

Follicles were punctured with a 25-gauge hypodermic needle attached to a 1-cc syringe in order to aspirate the granulosa cells (GC) [19]. The GC from each rat were pooled and layered over 5 $\mathrm{ml}$ of a $40 \%$ Percoll solution in order to remove red blood cells (RBC). The GC plus Percoll were centrifuged at approximately $500 \times \mathrm{g}$ for $25 \mathrm{~min}$ three times [20, 21]. After each centrifugation, the GC layer was aspirated from the top of the Percoll column to assure maximal recovery of GC. The purified GC were then counted in a hemacytometer and the concentration adjusted to 250,000 cells per $1.5 \mathrm{ml}$ centrifuge tube. GC were cultured in 
DMEM/F12 50/50 medium mixture (Mediatech, Herndon, VA, USA), with $5 \%$ fetal calf serum (FCS) and with $50 \mu \mathrm{g} / \mathrm{ml}$ gentamycin (Sigma Aldrich), in 5\% $\mathrm{CO}_{2}$ in compressed air and $98 \%$ relative humidity. Incubations were performed in duplicate. GC were cocultured with $2.85 \times 10^{10}$ particles/ml of $10 \mathrm{~nm}$ gold in medium for $24 \mathrm{~h}$. After incubation periods of $1,3,5$, and $24 \mathrm{~h}$, the cells were pelleted and medium samples were collected for estradiol (E2) radioimmunoassay (RIA). Control incubations followed the same procedure, but without nanoparticles. The GC were then fixed and embedded for analysis on a transmission electron microscope (TEM, Hitachi H-600, Hitachi, Pleasanton, CA).

Fixation and analysis of ovarian granulosa cells with the transmission electron microscope (TEM)

After incubating rat GC with $10 \mathrm{~nm}$ gold particles, GC were fixed with Karnovsky's fixative (2.5\% glutaraldehyde, 3\% paraformaldehyde in $0.1 \mathrm{M}$ sodium cacodylate buffer [CB]) for 30 min. Then the GC were washed three times for two min each with 0.1 M CB, pH 7.3 (Electron Microscopy Science, Fort Washington, PA, USA). GC were then pelleted for $5 \mathrm{~min}$ at $500 \times \mathrm{g}$. After the washings, each cell pellet was re-suspended in $100 \mu \mathrm{l}$ of a $2 \%$ sterile solution of sodium alginate (alginic acid-sodium salt, low viscosity; Sigma Aldrich) in saline. The mixture was transferred to a syringe with a 25-gauge needle. Microliter-sized amounts of the mixture were dropped into a $50-\mathrm{ml}$ sterile solution of $1 \% \mathrm{CaCl}_{2}$ in saline in order to obtain microspheres of GC suspended within the matrix of the cooled sodium alginate. The microspheres of GC were washed three times in $0.1 \mathrm{M} \mathrm{CB}$ and postfixed in $1.5 \% \mathrm{OsO}_{4}$ (Sigma Aldrich) in 0.1 M CB, pH 7.3, for $1 \mathrm{~h}$ at $25 \mathrm{C}$. The spheres were then washed with $0.1 \mathrm{M} \mathrm{CB}$ for approximately one min three times. GC in microspheres were serially dehydrated for $10 \mathrm{~min}$ each in a graded series of ethanol from 50 to $100 \%$. GC were infiltrated and embedded overnight in Eponate-12 embedding medium (Electron Microscopy Science, Fort Washington, Pa, USA) [21]. Sections were cut on an ultramicrotome and affixed to 200-mesh EM grids for analysis on the TEM. Images were taken from GC incubated in control medium and GC exposed to $10 \mathrm{~nm}$ nanogold in order to compare and contrast any ultrastructural differences in the GC themselves or in organelles among groups. TEM was also utilized to visualize the nanogold particles and to observe whether they entered or otherwise affected organelles inside the GC, and which organelles in particular. All nanoparticles crossing membranes (including nanoparticle agglomerates) were of interest in this study. We wished to evaluate all adverse reactions to the nanoparticles, whether singletons or agglomerates.

\section{Characterization of nanogold particles}

Nanogold particles $(10 \mathrm{~nm})$ were purchased suspended in double-distilled water from Nanocs (New York, NY) at a concentration of $5.7 \times 10^{12}$ particles $/ \mathrm{ml}$. They were then diluted in DMEM/F12 $50 / 50$ medium mixture with 5\% FCS (the same medium in which the cells were cultured), in order to validate whether there was any effect of the medium on the nanogold mixture. After the gold nanoparticles were diluted to the working solution concentration of $2.85 \times 10^{10}$ particles $/ \mathrm{ml}$, a $10 \mu \mathrm{l}$ volume of the solution was dropped onto four 400-mesh carbon/formvar-coated grids and

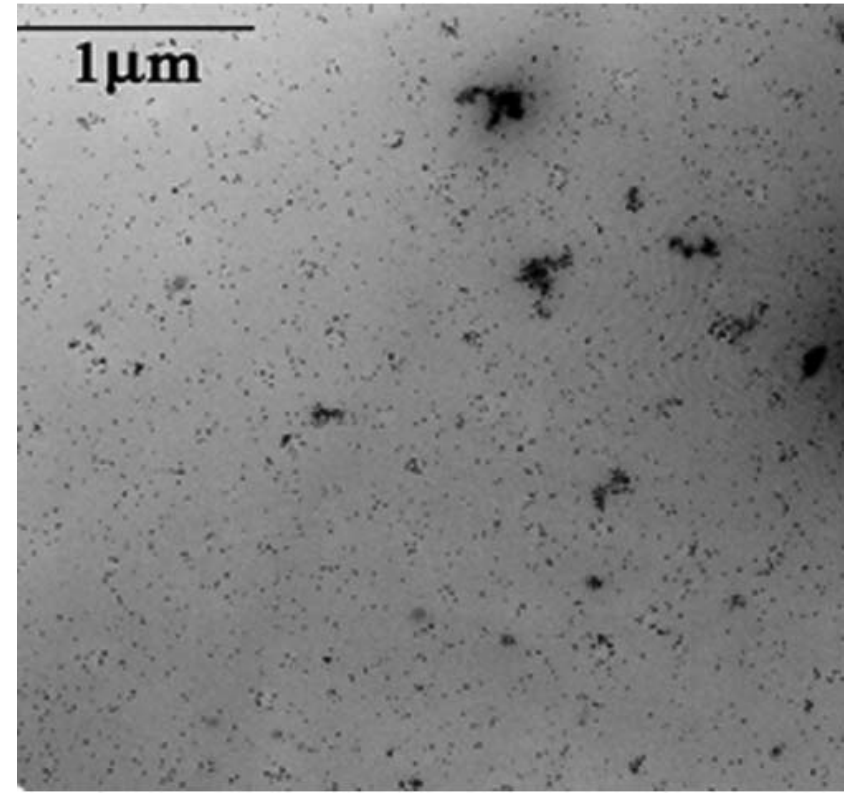

Fig. 1. Photomicrograph of $10 \mathrm{~nm}$ gold particles on 400-mesh formvarcoated grids.

allowed to dry. After drying the $10 \mu \mathrm{l}$ samples, the TEM was used at a voltage of $75 \mathrm{kV}$ in order to visualize the gold nanoparticles on the grids. After visualization of the gold, micrographs were taken of $10 \mathrm{~nm}$ gold samples at magnifications of $20000 \times$ (Fig. 1), 25000 $\times, 30000 \times$ and $50000 \times$. These images were then used as comparators for nanogold particles observed in all TEM micrographs of GC. Clumping or agglomeration of nanogold particles was sometimes observed outside (Fig.1) or within GC, and was most likely due to their coating with proteins within the serum in the complex culture medium, since no clumping was observed in distilled water (unpublished observations).

Radioimmunoassay (RIA) of supernatants from cell culture of granulosa cells incubated with $10 \mathrm{~nm}$ gold nanoparticles

GC from 16 rats were incubated with $10 \mathrm{~nm}$ nanogold particles over a period of $24 \mathrm{~h}$. Cells were pelleted at 1, 3, 5 or $24 \mathrm{~h}$ and medium samples were evaluated for E2 by RIA.

Coat-a-Count Radioimmunoassay Kits were obtained from Diagnostic Products Corporation (Los Angeles, CA), and previously validated for rat [19]. The basic RIA procedure was followed per the manufacturer's instructions but modified with additional 5 and $10 \mathrm{pg} / \mathrm{ml}$ standards. Binding of ${ }^{125} \mathrm{I}$ Estradiol was evaluated by counting each tube for one min on a gamma counter (Cobra II Autogamma, Packard, Downer's Grove, IL). Intra-assay and interassay variations were determined by using aliquots of a single pool of female rat serum (see below). Assay sensitivity was found to be 3 pg E2 per ml.

\section{Data analyses}

For analysis of E2 accumulation, GC were first pooled from preovulatory-sized ovarian follicles, and randomly allocated to 


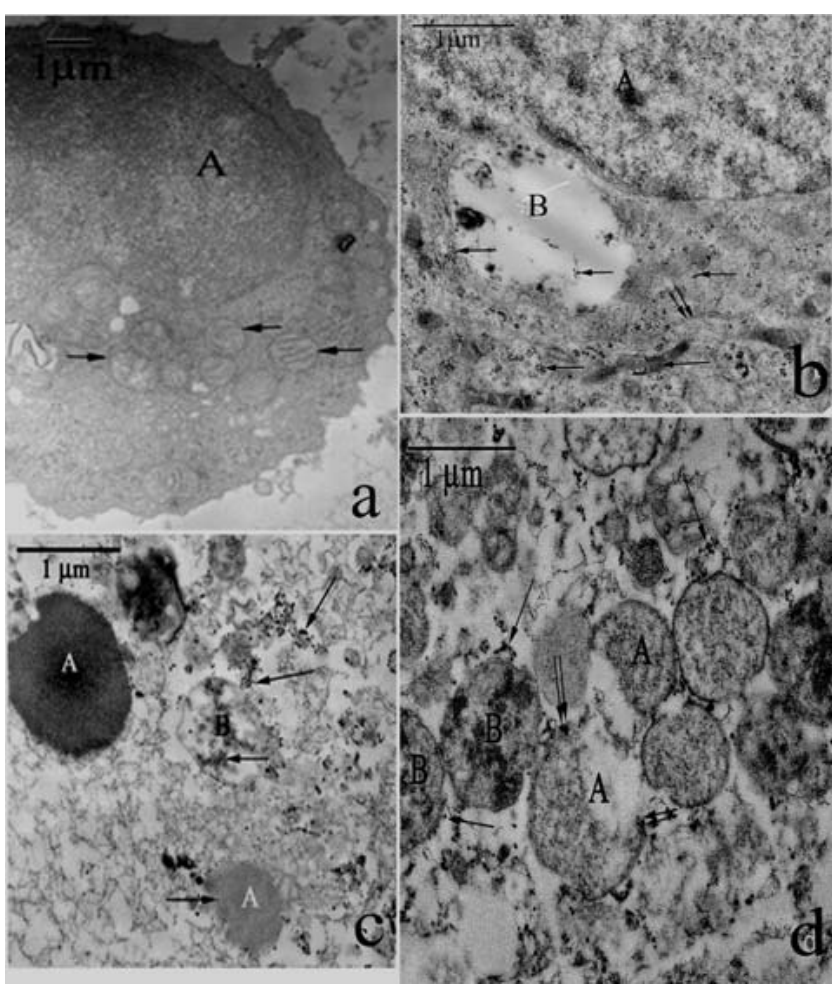

Fig. 2. (a) Control GC, at the 24-h incubation period, showing rounded mitochondria (single arrows); nucleus (A). (b) At the 3-h incubation period, nanogold particles are shown inside GC. Gap junctions are observed between the cells (double arrows). Gold nanoparticles (single arrows) are in the cytoplasm of the cell as well as shown inside a storage vacuole (B). Nucleus also shown (A). (c) At $5 \mathrm{~h}$, nanogold (single arrows) shown inside an apparently swollen, potentially damaged mitochondrion (B). Nanogold (single arrows) are shown inside lipid droplets (A). (d) At $24 \mathrm{~h}$, nanogold particles (single arrows) are shown in the cytoplasm of a GC near an undamaged mitochondrion (B). Nanogold particles (double arrows) are shown inside what appears to be a swollen mitochondrion with apparently damaged cristae (A).

treatment group (GC were either treated with nanogold particles or designated as control) and incubated in $1.5 \mathrm{ml}$ tubes. Samples of culture medium were assayed for E2 content according to the procedure described above. A total of four assays were performed with samples from nine experiments. E2 values from the pooled female rat serum samples (used as a baseline in each RIA assay) averaged $32.7 \mathrm{pg} / \mathrm{ml}$. The standard error of the mean and interassay coefficient of variation were determined to be $1.45 \mathrm{pg} / \mathrm{ml}$ and $16.6 \%$ respectively. The intra-assay coefficients of variation for each of the four assays performed were found to be: assay I= $14.45 \%$, assay $\mathrm{II}=4.66 \%$, assay $\mathrm{III}=10.84 \%$, and assay $\mathrm{IV}=11.02 \%$. All data were normalized to account for inter-assay variation; i.e. data adjustments were made by multiplying data by the percent difference between serum pool values from the individual E2 assays and the mean for all pooled samples. After data were normalized, analysis was performed using the SPSS Statistics Package (Chicago, IL). An initial analysis regarding mean E2 output (interaction of time and different-sized nanoparticles) was performed using a two-way analysis of variance (ANOVA, factors being time and nanoparticles). However, the nanoparticle size that could be easily visualized with TEM (i.e., $10 \mathrm{~nm}$ ) was only used in further analyses. Data at each separate time point, then, were analyzed between control and $10 \mathrm{~nm}$ by $t$-test, and depicted in Fig. 3 . In all cases, $\mathrm{P} \leq 0.05$ was considered to be significant.

\section{Results}

\section{Effect of $10 \mathrm{~nm}$ gold particles on ultrastructure of GC}

We observed some effects upon ultrastructure of GC when coincubated with $10 \mathrm{~nm}$ gold particles, compared with control GC (see Fig. 2a). Nanogold particles were observed to be in the cytoplasm of the GC by $1 \mathrm{~h}$ (not shown), and in cytoplasm and in vacuoles at $3 \mathrm{~h}$ (Fig. 2b). We observed $10 \mathrm{~nm}$ nanogold particles infiltrating lipid droplets of GC at 5 h (2c). Nanogold particles were also found in juxtaposition to the outer membrane of healthy mitochondria at the 24-h incubation time as well as inside apparently damaged, swollen mitochondria at both 5 and 24 h (2c, 2d). No translocation of $10 \mathrm{~nm}$ gold particles to any organelles of the GC other than mitochondria, lipid droplets or vacuoles was observed for any incubation period from $1 \mathrm{~h}$ to and including $24 \mathrm{~h}$.

\section{Effect of nanogold particles on E2 secretion by GC}

We evaluated mean E2 output with respect to the presence of nanoparticle at the various time periods using unpaired $t$-tests. Mean E2 output for the 1-, 3- and 5-h incubations of GC was significantly greater for $10 \mathrm{~nm}$ gold co-incubated with GC vs. untreated GC ( 1 h, df [number of samples in RIA] $=8, P=0.023$; $3 \mathrm{~h}, \mathrm{df}=5, \mathrm{P}=$ 0.006; 5 h, df=5, P=0.014) (Figs. 3a, 3b, 3c, respectively).

Mean E2 output for 24-h incubations of GC showed a significant decrease between GC co-incubated with $10 \mathrm{~nm}$ gold $v$ s. respective untreated GC ( $d f=4, P=0.034$ ) (Fig. 3d). The large amount of accumulated estradiol is due to the long-term culture over $24 \mathrm{~h}$, and the units are for the entire 24-h period and not normalized per $h$.

\section{Discussion}

We have demonstrated for the first time that nanoparticles can enter GC of the mammalian ovary and affect steroidogenesis. Coincubation of GC with gold nanoparticles (1) allowed nanoparticles to travel across GC membranes into organelles and potentially alter organelle ultrastructure, and (2) altered estradiol secretion/accumulation in a time-dependent manner. These are important observations since few studies have been published on translocation of nanoparticles into cells [18, 22-27], particularly cells of the female reproductive system. Researchers have reported movement of different types of nanoparticles to other areas of the body, but most of these studies described whole-animal studies with injection of nanoparticles or inhalation of these particles [16, 18, 23, 28]. These studies cited evidence for cellular uptake of nanoparticles by other cells of the body after traveling via the bloodstream or lymphatic system [18] and disturbing cellular processes.

Nanoparticles readily travel throughout the body, deposit in target organs, lodge in mitochondria and can trigger injurious 

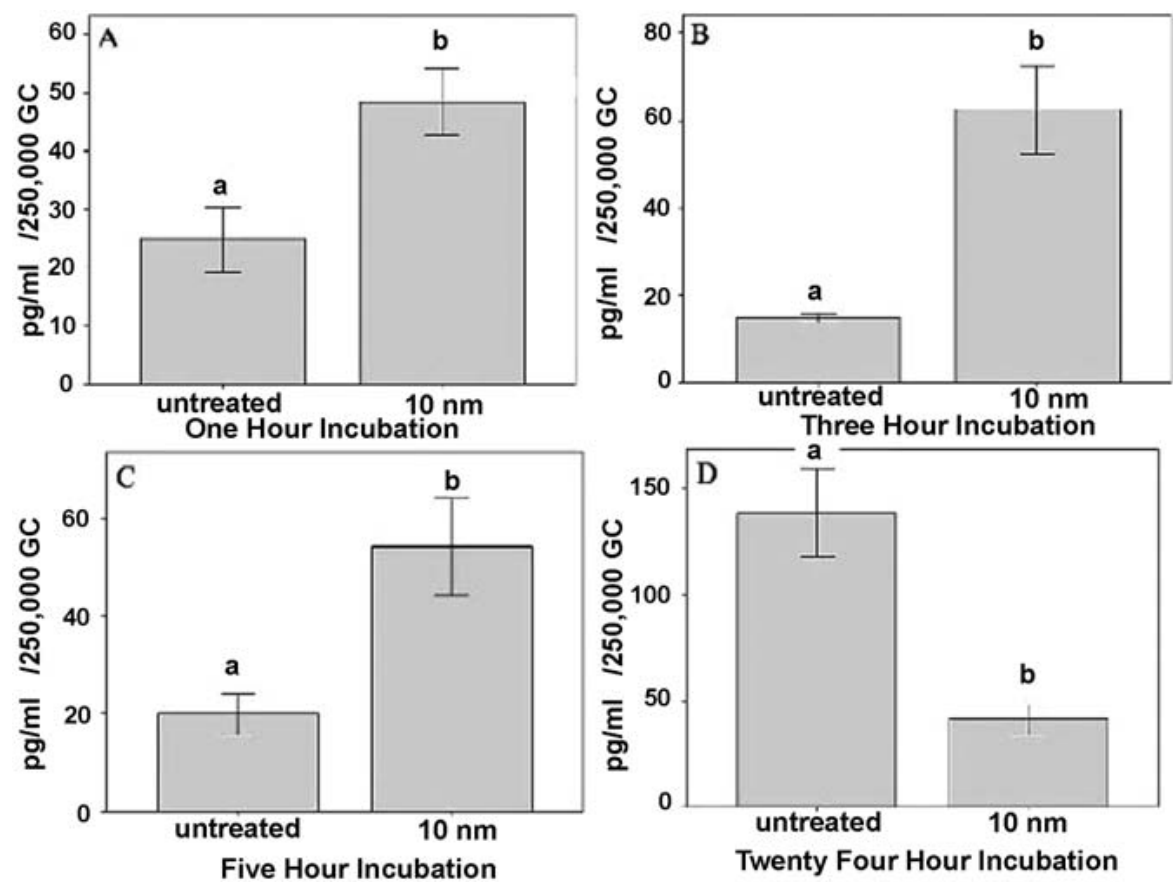

Fig. 3. (A) Mean output of $E 2$ in pg/ml per 250,000 GC ( \pm SEM) incubated with nanogold particles for $1 \mathrm{~h}$. (B) Mean output of E2 in pg/ml per 250,000 GC ( \pm SEM) incubated with nanogold particles for $3 \mathrm{~h}$. (C) Mean output of E2 in pg/ml per 250,000 GC ( \pm SEM) incubated with nanogold particles for $5 \mathrm{~h}$. (D) Mean output of E2 in pg/ml per 250,000 GC ( \pm SEM) incubated with nanogold particles for $24 \mathrm{~h}$. ${ }^{\mathrm{a}, \mathrm{b}}$ Differing superscripts designate statistically significant differences $(\mathrm{P}<0.05)$.

responses [29, 30]. Evidence has shown that nanoparticles disturb mitochondrial function and trigger oxidative stress, which makes it imperative that more basic research be performed regarding nanoparticle interactions with subcellular structures [15, 22, 31]. It is of great importance to us to study the toxicologic effects of nanoparticles because the exposure level of these particles is very high. It is estimated that $10^{12}-10^{14}$ nanoparticles are ingested per person per day in the Western world [31]. All of these particles have the potential to cause toxicologic responses in the body, especially the reproductive system (much of which is regulated by steroid hormones). It is therefore important to evaluate the effects nanogold particles exert on the steroidogenic GC cells of the ovary [32]. We expect that our research with nanogold can be used as a model to investigate how other types of nanoparticles may act on the ovary.

Our research specifically concluded that nanogold particles of $10 \mathrm{~nm}$ entered the GC and certain subcellular organelles, and modulated E2 secretion/accumulation by GC. The gold nanoparticles are blacker (i.e., more electron dense) than are mitochondrial ribosomes and because they appear larger they are probably agglomerated in groups of two or three particles. In our hands, we do see some clumping of nanogold particles in the medium ( $c f$. Fig 1 ), most likely due to interactions with proteins in the culture medium serum as the particles coat themselves with proteins. But whether they enter as single nanoparticles or clumps or become clumps inside cells, they do appear to cause effects on E2 release; and they do enter the GC and enter organelles such as the lipid droplets and mitochondria, potentially altering or damaging them.

After co-incubation with gold nanoparticles, GC E2 secretion/ accumulation was significantly different from basal control levels, depending upon the length of incubation. We observed increases in E2 accumulation by cells at 1, 3 and 5 h of incubation, while at 24 $\mathrm{h}$, there was a diminution in E2 secretion. The large amount of accumulated estradiol in control at $24 \mathrm{~h}$ is due to the long-term culture over $24 \mathrm{~h}$, and the units shown are for the entire 24-h period and not normalized per $h$.

After just $1 \mathrm{~h}$ of co-incubation with $10 \mathrm{~nm}$ gold nanoparticles there was a two-fold rise in E2 accumulation compared with GC incubated in the absence of nanogold. Our transmission electron micrographs of GC at $1 \mathrm{~h}$ of incubation suggested to us that this increase in $\mathrm{E} 2$ in the medium might be related to the nanogold particles moving across the cell and other membranes of GC (see Fig. 2). This is important because it is known that receptor-mediated endocytosis is the process by which nanoparticles are taken up by cells $[8,11,12,16,27]$. It is logical to believe, then, that the gold particles might be binding to membranes of the mitochondria thereby affecting their functions, and potentially altering activity of the side-chain cleavage (SCC) enzyme. This steroidogenic enzyme is located on the inner membrane of mitochondria and converts cholesterol to pregnenolone [33-35]. It is also conceivable that short-term nanogold co-culture increased permeability of mitochondria and of other organelles and cell membranes so as to augment E2 efflux from the cell and accumulation into the sur- 
rounding medium, but not necessarily enhancing synthesis/ secretion of E2 or its precursors so as to modulate actual steroidogenesis.

There might also be an increase in the amount of E2 released from the GC not only if cell membrane permeability were increased but also steroid precursor were released from storage in lipid droplets [33, 36, 37]. This seems logical based on our RIA data (refer to Fig. 3), as well as our electron micrographs (Fig. 2). We observed in our micrographs at 1 and $3 \mathrm{~h}$ of co-culture that nanogold was found near the outer membranes of mitochondria and inside mitochondria. If one then compares the RIA data at the same time periods, one finds that there is an increase in E2 accumulation. At $5 \mathrm{~h}$ of co-incubation, there is additional evidence for increased E2 accumulation. Based on our data we propose that this is due to altered permeability as stated above. At $5 \mathrm{~h}$ of incubation, our TEM micrographs show that there is nanogold infiltration into lipid droplets (see Fig. 2c), and possible disruption of some mitochondrial membranes. These micrographs in conjunction with our E2 data suggest that perhaps the nanogold inside the lipid droplets also allowed for efflux of free precursor steroid (or sterol such as cholesterol) for steroidogenesis, and estrogen accumulation could thereby be perceived to rise. However, at $24 \mathrm{~h}$, some mitochondria appeared disrupted or damaged (with loss of cristae [cf. Fig. 2d]), and this may have severely impaired the steroidogenic machinery, inhibiting E2 output by GC. There is evidence of receptor-mediated endocytosis causing nanoparticles to translocate to cells and alter mitochondrial function [8]. At $24 \mathrm{~h}$, there is also a dichotomous effect on steroid accumulation exhibited by the nanoparticles. The loss of mitochondrial function after efflux of accumulated steroid earlier (displayed in Fig. 2d) we believe to be the cause of the decreased E2 secretion of GC compared with control levels at this later time period. We hypothesize that there is so much putative disruption of mitochondria in the GC at 24 h that they cannot convert cholesterol to pregnenolone, and this therefore inhibits the subsequent production of E2.

Since there are no studies of nanoparticle effects on the female reproductive tract, much of our data must be interpreted without supporting information by other researchers regarding nanoparticles. It is logical to extend our experiments to evaluate potential disruption of specific steroidogenic enzyme genes and protein and StAR protein at the level of the mitochondria during incubation periods of 1,3 and 5 h to support our hypothesis, and we are doing so currently. It would be especially helpful to investigate the enzyme Cyp 11a (SCC), which directly converts cholesterol to pregnenolone in the mitochondria of GC [33-36, 38]. Follow-up studies in the more difficult in-vivo model system are planned so as to corroborate these endocrine-disrupting findings in the whole animal [39].

In conclusion, nanogold particles were observed in ovarian GC and within certain subcellular organelles, such as mitochondria, vacuoles, and lipid droplets. The infiltration of $10 \mathrm{~nm}$ nanogold particles apparently increased estradiol accumulation by (and presumably efflux from) GC at 1, 3 and 5 h. At 24 h, GC co-incubated with nanogold exhibited a drop in E2 secretion. This latter effect was possibly due to detrimental changes in mitochondria to the point that the conversion of cholesterol to pregnenolone was greatly reduced, inhibiting the eventual synthesis of E2 as well.

\section{Acknowledgements}

We gratefully acknowledge Dr H Owen for her technical assistance regarding TEM micrographs, and Dr R Klaper for assistance with nanoparticle methodologies. Research was supported in part by the College of Letters and Science, UWM.

\section{References}

1. Salata OV. Applications of nanoparticles in biology and medicine. J Nanobiotechnol 2004; $2: 3$.

2. Hillyer JF, Albrecht RM. Gastrointestinal persorption and tissue distribution of differently sized colloidal gold nanoparticles. J Pharm Sci 2001; 90: 1927-1936.

3. Hoet PHM, Bruske-Hohlfeld I, Salata OV. Nanoparticles-known and unknown health risks. J Nanobiotechnol 2004; 2: 12-20.

4. Kam NWS, Dai H. Carbon nanotubes as intracellular protein transporters: generality and biological functionality. J Am Chem Soc 2005; 127: 6021-6026.

5. Paciotti GF, Myer L, Weinrich D, Goia D, Pavel N, McLaughlin RE, Tamarkin L Colloidal gold: a novel nanoparticle vector for tumor directed drug delivery. Drug Deliv 2004; 11: 169-183.

6. Oberdorster G, Maynard A, Donaldson K, Castranova V, Fitzpatrick J, Ausman K, Carter J, Karn B, Kreyling W, Lai D, Olin S, Monteiro-Riviere N, Warheit D, Yang H. Principles for characterizing the potential human health effects from exposure to nanomaterials: elements of a screening strategy. Part Fibre Toxicol 2005; 2: 1743-1878.

7. Parak WJ, Gerion D, Pellegrino T, Zanchet D, Micheel C, Williams SC, Boudreau R, Le Gros MA, Larabell CA, Alivisatos AP. Biological applications of colloidal nanocrystals. Nanotechnol 2003; 14: R15-R27.

8. Rosi NL, Giljohann DA, Thaxton S, Lytton-Jean AKR, Han MS, Mirkin CA. Oligonucleotide-modified gold nanoparticles for intracellular gene regulation. Science 2006; 312: 1027-1030

9. Kreyling W, Semmler M, Erbe R, Mayer P, Takenaka S, Schulz H, Oberdorster G, Ziesenis A. Translocation of ultrafine insoluble iridium particles from lung epithelium to extrapulmonary organs is size dependent but very low. J Toxicol Environ Health 2002; 65A: 1513-1530.

10. Lam C, James JT, McCluskey R, Hunter RL. Pulmonary toxicity of single-wall carbon nanotubes in mice 7 and 90 days after intratracheal instillation. Toxicol Sci 2004; 77: 126-134

11. Tasat D, Gugliemotti MB, Cabrini RL. Titanium transport through the bloodstream an experimental study on rats. J Mater Sci Mater Med 2003; 14: 1099-1103.

12. Skukla R, Bansal V, Chaudhary M, Basn A, Bhonde RR, Sastry M. Biocompatability of gold nanoparticles and their endocytotic fate inside the cellular compartment a microscopic overview. Langmuir 2005; 21: 10644-10654.

13. Wiley C. Nanotechnology and molecular homeostasis. J Am Geriat Soc 2005; 53: S295S298.

14. Yamawaki $\mathbf{H}$, Iwai $\mathbf{N}$. Cytotoxicity of water-soluble fullerene in vascular endothelial cells. Am J Physiol Cell Physiol 2006; 290: C1495-C1502.

15. Oberdorster G, Oberdorster E, Oberdorster J. Nanotoxicology: an emerging discipline evolving from studies of ultrafine particles. Environ Health Perspect 2005; 113 823-839.

16. Chithrani DB, Ghazani AA, Chan WCW. Determining the size and shape dependence of gold nanoparticle uptake into mammalian cells. Nano Lett 2006; 6: 662-668.

17. Roy I, Ohulchanskyy TY, Bharali DJ, Pudavar HE, Mistretta RA, Kaur N, Prasad PN. Optical tracking of organically modified silica nanoparticles as DNA carriers: A nonviral nanomedicine approach for gene delivery. Proc Natl Acad Sci USA 2005; 102 279-284.

18. Geiser M, Rothen-Rutishauser B, Kapp N, Schurch S, Kreyling W, Schulz H, Semmler M, Hof VIM, Heyder J, Gehr P. Ultrafine particles cross cellular membranes by nonphagocytic mechanisms in lungs and in cultured cells. Environ Health Perspect 2005; 113: 1555-1560.

19. Dasmahapatra AK, Wimpee BA, Trewin AL, Wimpee CF, Ghorai JK, Hutz RJ. Demonstration of 2,3,7,8-tetrachlorodibenzo-p-dioxin attenuation of P450 steroidogenic enzyme mRNAs in rat granulosa cell in vitro by competitive reverse transcriptase polymerase chain reaction assay. Mol Cell Endocrinol 2000; 164: 5-18.

20. Heimler I, Rawlins RG, Owen H, Hutz RJ. Dioxin perturbs, in a dose- and timedependent fashion, steroid secretion, and induces apoptosis of luteinized granulosa cells. Endocrinol 1998; 139: 4373-4379.

21. Heimler I. Perturbation of ovarian function by $2,3,7,8$-tetrachlorodibenzo- $P$-dioxin 
Dissertation for requirements for the degree of doctor of philosophy in biological Sciences at the University of Wisconsin-Milwaukee 1997.

22. Braydich-Stolle L, Hussain S, Schlager JJ, Hofmann M. In vitro cytotoxicity of nanoparticles in mammalian germline stem cells. Toxicol Sci 2005; 88: 412-419.

23. Donaldson K, Tran L, Jimenez LA, Duffin R, Newby DE, Mills N, MacNee W, Stone V. Combustion-derived nanoparticles: A review of their toxicology following inhalation exposure. Part Fibre Toxicol 2005; 2: 1743-1770.

24. Hardman R. A toxicologic review of quantum dots: toxicity depends on physicochemical and environmental factors. Environ Health Perspect 2006; 114: 165-172.

25. Hayat MA. Principles and Techniques of Electron Microscopy Biological Applications. $4^{\text {th }}$ ed. New York: Cambridge University Press; 2000.

26. Chen Y, Xue Z, Zheng D, Xia K, Zhao Y, Liu T, Long Z, Xia J. Sodium chloride modified silica nanoparticles as a non-viral vector with a high efficiency of DNA transfer into cells. Curr Gene Ther 2003; 3: 273-279.

27. Prina-Mello A, Diao Z, Coey JMD. Internalization of ferromagnetic nanowires by different living cells. J Nanobiotechnol 2006; 4: 9.

28. Kashiwada S. Distribution of nanoparticles in the see-through Medaka (Oryzias latipes). Environ Health Perspect 2006; 114: 1697-1702.

29. Keegan GM, Learmonth ID, Case CP. Orthopaedic metals and their potential toxicity in the arthroplasty patient. J Bone Jt Surg 2007; 89: 567-573.

30. Nel A, Xia T, Madler L, Li N. Toxic potential of materials at the nanolevel. Science
2006; 311: 622-627.

31. Borm PJA, Robbins D, Haubold S, Kuhlbusch T, Fissan H, Donaldson K, Schins R, Stone V, Kreyling W, Lademann J, Krutmann J, Warheit D, Oberdorster E. The potential risks of nanomaterials: a review carried out for ECETOC. Part Fibre Toxicol 2006; 3: 1186-1221.

32. Richards JS. Perspective: The ovarian follicle—a perspective in 2001. Endocrinol 2001; 142: 2184-2193.

33. Goodman MH. Basic Medical Endocrinology. $2^{\text {nd }}$ ed. New York: Raven Press, 1994

34. Hadley ME. Endocrinology. $2^{\text {nd }}$ ed. New Jersey: Prentice Hall, 1988.

35. Jamnongjit M, Hammes SR. Ovarian steroids: the good, the bad, and the signals that raise them. Cell Cycle 2006; 5: 1178-1183.

36. Amsterdam A, Knecht M, Catt KJ. Hormonal regulation of cytodifferentiation and intercellular communication in cultured granulosa cells. Proc Natl Acad Sci USA 1981; 78: 3000-3004.

37. Amsterdam A, Berkowitz A, Nimrod A, Kohen F. Aggregation of luteinizing hormone receptors in granulosa cells: A possible mechanism of desensitization to the hormone. Proc Natl Sci USA 1980; 77: 3440-3444.

38. Dive C, Yoshida TM, Simpson DJ, Marrone BL. Flow cytometric analysis of steroidogenic organelles in differentiating granulosa cells. Biol Reprod 1992; 47: 520-527.

39. Guillette LJ. Endocrine disrupting contaminants-beyond the dogma. Environ Health Perspect 2006; 114 (Suppl 1): 9-12. 